\title{
Challenges of Implementation of the National Phenylketonuria Screening Program in Iran: A Qualitative Study
}

\author{
Alireza Heidari ${ }^{1}$, Mohammad Arab $^{2}$, Koorosh Etemad ${ }^{3}$, Behzad Damari ${ }^{4}$, Mohammad Javad Kabir ${ }^{5}$
}

${ }^{1}$ Ph.D. Candidate of Health Policy, Department of Management and Health Economic, School of Public Health, Tehran University of Medical Sciences, Tehran, Iran

${ }^{2}$ Professor, Health Services Management, Department of Management and Health Economic, School of Public Health, Tehran University of Medical Sciences, Tehran, Iran

${ }^{3}$ Assistant Professor, Department of Epidemiology, Environmental and Occupational Hazards Control Research Center, Faculty of Public Health, Shahid Beheshti University of Medical Sciences, Tehran, Iran

${ }^{4}$ Assistant Professor, Community Medicine, Department of Social Determinant of Health, National Institute of Health Research, Tehran University of Medical Sciences, Tehran, Iran

${ }^{5}$ Assistant Professor, Health Services Management, Health Management and Social Development Research Center, Golestan University of Medical Sciences, Gorgan, Iran

\section{Type of article: Original}

\begin{abstract}
Introduction: Newborn screening (NBS) is a public health measure aimed at identification of early cases, management of afflicted infants, and making efforts to reduce the morbidity and mortality among newborns. All countries may face challenges in implementation of screening programs. The present study aimed to determine the challenges of implementation of the National Phenylketonuria (PKU) Screening Program in Iran.

Methods: In this qualitative study, 38 health policymakers, managers, and PKU experts in Iran were purposively selected as the respondents in 2015. The semi-structured interview was used for collecting the required data and information. After transcription of interviews, their content was analyzed using framework analysis.

Results: The results were categorized into five main themes and 22 subthemes. The main themes extracted from data were management challenges, diagnosis challenges, treatment challenges, care challenges, and patients' family problems. Each category consisted of several subthemes.

Conclusion: Considering the challenges of implementing this program, some measures such as increased stability of managers in the health system, greater interaction of the Ministry of Health and Medical Education with the heath stakeholders, improving the level of parents' awareness, the use of efficient information systems, support and legal backing for requiring parents who refuse newborn screening for various reasons, and appropriate insurance coverage seem necessary to be taken.
\end{abstract}

Keywords: Challenges, Phenylketonuria, Screening, Iran

\section{Introduction}

PKU is an autosomal recessive disorder resulting from dysfunction in the activity of phenylalanine hydroxylase (PAH), which is necessary for metabolizing of phenylalanine to tyrosine in the liver. This leads to increased phenylalanine concentration in the blood and eventually the brain. Accumulation of phenylalanine and its metabolites without appropriate intervention during infancy leads to the occurrence of progressive cognitiveneurological damages in newborns (1). High levels of phenylalanine in the plasma typically cause mental disability, seizure, behavioral problems, and delay in motion and language evolution (2). The incidence of PKU may vary in different ethnic communities. For example, a high incidence of disease has been reported in Turkey (one in every

\section{Corresponding author:}

Professor Dr. Mohammad Arab, Health Services Management, Department of Management and Health Economic, School of Public Health, Tehran University of Medical Sciences, Tehran, Iran.

Tel: +98.2188989128, Fax: +98.2188989129, Email: arabmoha@tums.ac.ir

Received: April 14, 2016, Accepted: July 12, 2016, Published: October 2016

iThenticate screening: June 28, 2016, English editing: July 26, 2016, Quality control: August 02, 2016

(C) 2016 The Authors. This is an open access article under the terms of the Creative Commons Attribution-NonCommercialNoDerivs License, which permits use and distribution in any medium, provided the original work is properly cited, the use is non-commercial and no modifications or adaptations are made. 
2600 newborns), while this figure is much lower (one in every 100,000 births) in some other countries such as Finland and Japan (3). Early diagnosis and taking appropriate measures in the case of a positive screening result can reduce disability and even death among the afflicted newborns (4). Newborn screening (NBS) is a public health measure aimed at identification of early cases, management of afflicted infants, and making efforts to reduce morbidity and mortality among newborns. NBS is a comprehensive system of education, screening, follow-up, diagnosis, treatment/management, and evaluation, which should be institutionalized and consolidated in the public health system of a country (5). In smaller countries that do not have any NBS program for PKU, only a few cases of patients with PKU have been reported. In these countries, training of medical personnel to manage PKU and even to obtain any clinical symptoms of PKU is difficult. In addition, the exact diagnosis of PKU without NBS is impossible and may lead to the wrong estimation of incidence and inaccurate planning for intervention programs (6).

The incidence of PKU is high in Iran (2); thus, the incidence of the disease was 1 in 10,000 in the Karamifar et al. study (7) and 1.6 in 10,000 in the Habib et al. study (8). The PKU screening program began in Iran in 2006 and blood samples of newborns are taken on the third to fifth days of birth for screening, and newborns with a phenylalanine level of $4 \mathrm{mg} / \mathrm{dL}$ or higher are referred for HPLC test for diagnosis confirmation. Then, regular follow-up is done for those who have a phenylalanine level equal to or higher than $4 \mathrm{mg} / \mathrm{dL}$. If the level of phenylalanine is higher than $7 \mathrm{mg} / \mathrm{dL}$, a diet with phenylalanine restriction is prescribed for these newborns. In addition, food supplements such as iron, zinc, selenium, carnitine, vitamins, and essential fatty acids are prescribed to all afflicted newborns up to two years (9). Although all countries face challenges in implementing the screening programs, developing countries may face more challenges, which are attributed to weak economic conditions, political instability, unique culture, geographic range, and various priorities in the field of public health (5). Given the fact that achieving the predetermined objectives of each program requires the assessment of its implementation and the program challenges may hinder the enjoyment of the community from the existing services, the present study aimed to determine the challenges of implementation of the national Phenylketonuria (PKU) Screening Program in Iran. It is hoped that the results of this study will be applied for resolving or minimizing the weaknesses and realizing all objectives of this screening program.

\section{Material and Methods}

The present research was a qualitative, descriptive, and cross-sectional study, which was carried out in 2015. In this study, 38 experts of health policymakers, managers, and PKU experts in Iran were purposefully selected as the respondents using the documents and organizational chart of organizations involved in the development and implementation of policies and programs of phenylketonuria screening, including the Ministry of Health and Medical Education (Department of Health and Department of Treatment, the Policymaking Council, Food and Drug Administration, pediatric hospitals, Genomics Research Center, and faculty members), Ministry of Cooperatives, Labor and Social Welfare (The Iranians Health Insurance and the State Welfare Organization), Pasteur Institute (the national reference laboratory for inherited metabolic diseases), the Health Commission of the Islamic Consultative Assembly, PKU Patients Support Association, and patients' parents. These individuals were selected using the snowball method based on some criteria such as having specialized knowledge on PKU, having experience and familiarity with PKU screening programs, being interested in participating in the research, active participation in PKU screening programs, and being the representative of one of the organizations or bodies associated with PKU screening programs. To elicit the opinions and views of the experts, the semi-structured interview method with interview guidelines was used. In addition, instead of using terms such as "data validity" and "data reliability," some criteria such as credibility, transferability, dependability, and conformability were used. The interviews were conducted by the authors at a specified time and place. Before starting the interviews, the interviewees were briefed on the research objectives. With the permission of the interviewees and, after assuring them about confidentiality of their information, interviews were recorded and then transcribed as soon as possible. Data analysis was done using framework analysis, which includes five steps of familiarization, identification a thematic framework (indexing), charting, mapping, and interpretation.

\section{Results}

In this qualitative study, five main themes and 22 subthemes were extracted (Table 1).

\subsection{Management challenges}

3.1.1. Senior managers of the Ministry of Health and Medical Education are changed quickly:

"Senior managers of the Ministry of Health and Medical Education were changed very quickly and changes in policies are to the detriment of the program" (Interviewee 28). 
Table 1. Challenges of Implementation of the National PKU Screening Program

\begin{tabular}{|c|c|}
\hline Theme & Subtheme \\
\hline \multirow{5}{*}{$\begin{array}{l}\text { Management } \\
\text { challenges }\end{array}$} & Senior managers of the Ministry of Health and Medical Education are changed quickly \\
\hline & There is no outlook in planning for the future \\
\hline & Inter-sectoral and intra-sectoral cooperation is weak \\
\hline & $\begin{array}{l}\text { There is no comprehensive information system that constantly provides updated data on } \\
\text { all diseases }\end{array}$ \\
\hline & There is no convenient payment system \\
\hline \multirow[t]{3}{*}{ Diagnosis challenges } & $\begin{array}{l}\text { Sample diagnosis confirmation is faced with some difficulties in provinces due to the } \\
\text { lack of HPLC }\end{array}$ \\
\hline & The quality of filter papers is low in some universities that affects the test result \\
\hline & Backup Elisa did not exist in many laboratories \\
\hline \multirow[t]{4}{*}{ Treatment challenges } & $\begin{array}{l}\text { There is weak cooperation and collaboration between the health care team and hospital's } \\
\text { pharmacy }\end{array}$ \\
\hline & Medical students were not adequately trained to care patients with PKU \\
\hline & Duties of the trained specialist doctor was assigned to residents \\
\hline & Shortage of special milk for PKU patients \\
\hline \multirow[t]{4}{*}{ Care challenges } & Delays and problems in diagnosis and referral \\
\hline & $\begin{array}{l}\text { The referral rate was low in some provinces due to insufficient social awareness and } \\
\text { information }\end{array}$ \\
\hline & $\begin{array}{l}\text { Withdrawal from treatment occurs in adulthood, and the system has a low level of control } \\
\text { on these patients }\end{array}$ \\
\hline & $\begin{array}{l}\text { Some participants commented that the hospital and non-hospital information on PKU is } \\
\text { not appropriately recorded }\end{array}$ \\
\hline \multirow[t]{6}{*}{$\begin{array}{l}\text { Challenges of patients' } \\
\text { family }\end{array}$} & $\begin{array}{l}\text { Due to the poor financial status of patients' parents, they have financial problems } \\
\text { because they should pay high medical and nonmedical costs }\end{array}$ \\
\hline & Parents of newborns with PKU are unaware \\
\hline & The efficiency of other members of a family with a PKU patient reduces to a high extent \\
\hline & $\begin{array}{l}\text { Some of the respondents believed that the social stigma of this disease is one of the } \\
\text { obstacles of this program }\end{array}$ \\
\hline & Parenting skills in parents and self-care in patients are weak \\
\hline & Some participants pointed to the problems of caring for a PKU patient \\
\hline
\end{tabular}

\subsubsection{There is no outlook in planning for the future:}

"In PKU screening program, policymakers should have long-term attitude toward national policymaking. We have no plan for the next 10 years. Policies and programs rapidly change in the Ministry of Health and Medical Education because they are dependent on individuals and not a system" (Interviewee 19).

3.1.3. Inter-sectoral and intra-sectoral cooperation is weak:

"The organizations involved in this field do not have a good interaction with each other, and it is not good at all. Sometimes this is unavoidable in our country. For these works, inter-sectoral and intra-sectoral committees should be established" (Interviewee 26).

3.1.4. There is no comprehensive information system that constantly provides updated data on all diseases:

"Our worse problem in the Ministry of Health and Medical Education is that we still do not have a comprehensive information system that constantly provides updated data on all diseases, risk factors, and conditions in different parts of the country, and managers have to rely on scattered and unclassified information" (Interviewee 16).

3.1.5. There is no convenient payment system:

"We are working in a network that has an illogical payment system. We must reform our payment system. We must define a fixed payment in the system and set the final payment based on the performance base" (Interviewee 10).

\subsection{Diagnosis challenges}

3.2.1. Sample diagnosis confirmation is faced with some difficulties in provinces due to the lack of HPLC:

"At the beginning of implementation of this program throughout the country, some provinces had difficulty to confirm the diagnosis because they unfortunately did not have the required equipment for HPLC" (Interviewee 10). 
3.2.2. The quality of filter papers is low in some universities that affect the test result:

"According to the climate difference between the warmest and the coldest points in our country, these filter papers are kept under high temperature and humidity. This alters the stability of the sample and affects the test results" (Interviewee 9).

3.2.3. Backup Elisa did not exist in many laboratories:

"There is no Backup Elisa in many laboratories. Suppose that one the devices gets out of work, what would we do for the samples?" (Interviewee 9).

\subsection{Treatment challenges}

3.3.1. There is weak cooperation and collaboration between the health care team and hospital's pharmacy:

"Entrustment of the selected hospital's pharmacy to the private sector reduced the level of cooperation in the implementation of the program. The doctors did not cooperate and said that I have my own patients and nothing to do with PKU" (Interviewee 22). "The nutrition expert does not have a good relationship with our endocrinology and metabolism expert. Pharmacy has been entrusted to the private sector, and they say that we cannot keep the milk" (Interviewee 19).

3.3.2. Medical students were not adequately trained to care patients with $P K U$ :

"Our students do not see the patients. Necessary coordination should be made with the selected centers in order to provide the conditions for students to visit the cases. In addition, educational units should organize the rotations" (Interviewee 2).

3.3.3. Duties of the trained specialist doctor were assigned to residents:

"Training hospitals have their own conditions and charts. This program was assigned to residents and interns, and residents are rapidly changed. Some of them are not familiar with the PKU screening program, and they do not know how the referral system for PKU works" (Interviewee 28).

3.3.4. Shortage of special milk for PKU patients:

"The number of patients should be specified for the Food and Drug Administration, so that they can estimate how much special milk should be ordered for the next year. Sometime we have a shortage of milk" (Interviewee 13). "In terms of milk supply, we occasionally face some problems. The actual definition of depot must be considered, not only throughout the country and universities but also in smaller levels. We should have an acceptable depot, so that we will have no concern in this regard" (Interviewee 11).

\subsection{Care challenges}

3.4.1. There are delays and problems in diagnosis and referral:

"The newborns who should be examined for non-classical PKU may refer late or we may give them the results with delay" (Interviewee 2). "Referral is done since the first screening. The result must be given to families. Then, after the person is found, he/she should be informed for definite diagnosis. After diagnosis confirmation, the newborn should be taken to the selected hospital to start the special diet. Sometimes this may be a lengthy process and affect the newborn" (Interviewee 28).

3.4.2. The referral rate was low in some provinces due to insufficient social awareness and information:

"We implemented this program in some areas but people referred less. They were not enough justified about why they should go and do the heel blood test. Although the program was going on, there was no social information or awareness about it" (Interviewee 16).

3.4.3. Withdrawal from treatment occurs in adulthood, and the system has a low level of control on these patients: "Treatment withdrawal increases as the patients become adults and then control on these patients gets weaker" (Interviewee 28).

3.4.4. Some participants commented that the hospital and non-hospital information on PKU is not appropriately recorded:

"One of the problems is that the hospital information is not properly recorded. This is also true about non-hospital information because the health system in Iran is communicable-oriented. However, this style is not good for noncommunicable diseases" (Interviewee 2).

\subsection{Challenges of patients' family}

3.5.1. Due to the poor financial status of patients' parents, they have financial problems because they should pay high medical and non-medical costs:

"This disease is not like other diseases that we cure it and tell the patient to come for a visit: for example, one year later. This disease and its treatment process should be followed-up in short intervals, which burdens high costs on patients' family" (Interviewee 7). "Diet of a newborn with PKU and the milk and food he/she must consume are 
expensive. If the patient has seizures and is mentally disabled or he/she has delay in movement and speech, he/she will need speech therapy. All of these can put financial burden on the shoulders of families" (Interviewee 12).

3.5.2. Parents of newborns with PKU are unaware:

"In this center, we are in contact with parents who rarely have an education degree higher than a high school diploma and also are not in a good financial status. These issues make our work more difficult. However, when a person is educated, he/she can understand more easily when you explain something" (Interviewee 12).

3.5.3. The efficiency of other members of a family with a PKU patient reduces to a high extent:

"If there is a disabled person in a family, caring for him/her may highly reduce the efficiency of other members. For example, a mother said, 'My daughter hates my newborn who has PKU because our first priority in expenses is our sick newborn; we should first pay for the food and treatment of our patient and then the remaining is spent on other healthy children" (Interviewee 20).

3.5.4. Some of the respondents believed that the social stigma of this disease is one of the obstacles of this program: "We have a big problem with the social stigma attached to these patients that makes it difficult treat and follow them up. A person who has a child with PKU does not reveal it even to his/her brother or sister" (Interviewee 36).

3.5.5. Parenting skills in parents and self-care in patients are weak:

"These are parents who fall into the hands of patient management. A mother who has a disabled child in the family may face problems and difficulty in parenting skills and disease management" (Interviewee 17).

3.5.6. Some participants pointed to the problems of caring for a PKU patient:

"PKU is not a common disability. It requires three shifts of nursing" (Interviewee 2). "Our newborn was not diagnosed with PKU through screening. He/she was restless and always crying in parties. My husband told me that your family has not taught you how to calm the baby down. Others also teased me" (Interviewee 23).

\section{Discussion}

NBS started in various populations in many developed countries nearly three decades ago (10). Currently, virtually all industrialized countries and many developing countries are systematically performing NBS. The heavy burden caused by neonatal diseases has made countries develop and execute screening programs for this disease and other metabolic diseases (11). One of the management challenges of this program was to deal with rapid changes in the health system managers, which negatively affect the implementation of policies and screening programs for PKU. This is consistent with the findings of Romdhane et al. (12): unlike many developed countries where displacement of managers is not typically associated with the occurrence of political changes, the position of managers in Iran falters with any political event, which causes confusion and delay in implementation of programs (13). Weak intersectoral and intra-sectoral cooperation was another management challenge in this regard. According to the study conducted by Ozalp et al. (2001), there is a need for a regular inter-sectoral approach, more than what exists now, for screening and treatment of all newborns with PKU (14). In a study conducted by Han and Lee to assess the newborn screening system based on data from years 1991-2002 in South Korea, lack of an organization responsible for coordination was reported as one of the problems (15). The lack of culture building and inter-sectoral compassion are among the reasons for the weak inter-sectoral cooperation in this field. The mechanism of decisionmaking in Iran is such that most contacts between planners and experts of different areas occur at the time of program presentation. Such contacts cannot make for exchanging of ideas and inter-sectoral team-building. Repetition of joint training programs can be helpful in this case. In terms of insufficient inter-sectoral cooperation in the Ministry of Health and Medical Education, program-based competitions between different departments that occur during the advancement of works under pressure of rapid implementation need to be further addressed (16).

One of the challenges of treatment in the selected hospitals for PKU is inadequate training of residents and assignment of duties of specialist doctors to them. Evaluation of clinical teaching of medical students and residents in the selected hospitals for PKU seems to be necessary. Coordination between theoretical and practical courses, evaluation of educational methods and practical skills training, the mentorship approach for supervision of first-year medical students by senior students and close supervision of professors and physicians on treatment processes and providing feedback to students are recommended for improving the status quo. Poor teamwork was another challenge in the treatment process. The results of a study conducted by Kalisch et al. (2010) showed that the stronger the teamwork, the lower the risk of forgetting the nursing care and the higher the job satisfaction (17). In order to improve the conditions of teamwork, its main coordinating mechanisms should be taken into account. These mechanisms include having a strong leader for coordination of members' activities and evaluation of activities, motivating the members and improving their knowledge and skills, bilateral monitoring of activities for the recognition of the team environment, volume of works and even members' fatigue, anticipation of members' needs, the ability to implement team strategies based on gathered information, creating an atmosphere of trust between 
members, and exchange of information between individuals (18). The findings of Chakraborti et al. (2008) revealed that effective training of teamwork reduces the medical errors of students (19). Therefore, holding practical workshops for managers and employees in healthcare medical organizations can be effective in the improvement of teamwork.

Another treatment challenge was temporary shortage of special milk for PKU patients. For solving this problem, the Food and Drug Administration has recently organized a supply and distribution chain for metabolic and dietary dry milk for PKU patients. This program was performed with the aim of proper and reasonable prescription services, preventing dealership and intermediation, laying the groundwork for better planning, avoiding travel costs, reducing the possible risk of providing these products from special centers, dealing with possible shortages, correct assessment of annual consumption, and creating mental comfort for consumers. One of the barriers against the implementation of a PKU screening program is the high costs of diagnosis, treatment, rehabilitation, and care services. Given that most of these services are not covered by insurance, and the majority of patients are not financially in a good status; they have to pay the costs from their own pocket. This may lead to withdrawal of families from these services, not following-up the treatment process, and occurrence of irreversible mental handicaps for the patient. According to Padilla and Therrell (2007), the weak economy of countries was one of the challenges in the implementation of the NBS in the Western Pacific region (20). Mei et al. reported that poor financial support is one of the challenges of NBS (21). According to Borrajo (2007), financing of screening programs in Latin America countries was found to be one of the effective economic factors (22). The results of a study conducted in South Korea by Han and Lee (2003) showed that the limited financial support of the government has made families of PKU patients pay the cost of PKU diagnosis test out of their own pocket (23). The findings of Ayé et al. (2010) in Tajikistan showed that financial factors are the most impeding barriers against the enjoyment of diagnosis services (24). The results of a study conducted by Van Doorslaer (2006) in 11 Asian countries indicated that increased payment from public funds negatively affects the household use of health services. These payments also could leave disturbing effects on the living standards of households. Lack of full insurance coverage has made families pay high costs and has led toward poverty (25). High reliance on financing through direct payment from public funds in most developing countries has shown that this system may cause families to face unforeseen health costs. Occurrence of a disease can put families into a dilemma about spending for medical costs or taking risks to ignore it, which could lead to deterioration of health status (26). Increased poverty resulting from the high costs of health care causes social health insurance to be raised as a way to reasonably finance these costs. In insurance protection policies, insurance premiums and benefits packages for low-income or unemployed workers in the informal sector should be motivating enough to encourage all of them to join this insurance coverage (27). An important cultural factors is the ignorance of families about PKU. This is consistent with the findings of Huang et al. (2005) in southern Taiwan (28) and Borrajo (2007) in Latin American countries (22) but inconsistent with the results of Campbell and Ross (2003) in the United States (29). Unawareness of parents about the disease can be due to their low health literacy. According to studies, ignorance and low health literacy level of parents makes people care less about their own and children's health and refer with delay for diagnosis, treatment, and follow-up of possible diseases. Under the terms of the NBS policy document in Alberta, Canada, published in March 2010, if parents refuse screening for their children, they should be aware of the purpose of testing and possible problems resulting from the refusal (30).

One of the problems for the implementation of the PKU screening program was delay in timely diagnosis of cases. According to studies conducted by Morovatdar et al. (31) in North Khorsan, Iran, Eshraghi et al. (32) in Mazandaran, Iran, Vela et al. (33) in Mexico, Takano and Stranieri (2009) in Brazil (34), and Ades et al. (2001) in England (35), the average age of diagnosis of patients with PKU is 19 months, 20 months, 32 months, 12 days, and 14.5 days, respectively. In order to reduce this delay, training the parents of newborns after childbirth by hospital personnel on screening tests and rapid notification of positive cases to parents by health care teams seem to be necessary. One of the problems of this program was recording of hospital services. In a study conducted by Ades et al. in order to calculate the coverage rate of NBS, report of births from newborns' health systems was electronically sent to the computer system of newborns. Then, the sample cards received by the laboratory were compared with the birth cases and reports, and the obtained data were analyzed for assessment of the coverage rate of the program. The results revealed a coverage rate of $99.5 \%$, which was much higher than the standards set in previous studies (35). Tomasi et al. (2004) showed that the electronic record of patients' data even in primary care is associated with advantages such as correct registration of information, spending less time, more efficient use of economic resources, and more quickness and easiness in information retrieval (36). To resolve this problem, authorization of abovementioned processes throughout the country is recommended. Improved quality and accuracy of the services 
provided and registration of relevant information reduced individual errors in recording of information, reduced repetitive and time-consuming tasks, saving in miscellaneous expenses, and reduced manpower are some of the advantages of using software systems (37). It was difficult to secure the cooperation of screening centers and participants in this study. This problem was resolved through the university correspondence, continuous pursuit, and explanation of the research importance. The absence of full cost information was another problem in this study, which was overcome using the views and comments of the relevant authorities and also documents of other affiliated units. Few studies have been conducted in this field, so this limitation was tried to be partly compensated by reviewing similar studies in other countries. Due to the high workload of interviewees, the interviews were tried to be performed in times when they had no concern. Sometimes, despite all arrangements, the interviewers had to travel to a place for conducting the unreview several times.

\section{Conclusions}

This study showed that the National PKU Screening Program has faced management, diagnosis, treatment, care challenges, and patients' family problems. This study indicated a gap between present and desired status in implementation of the PKU Screening Program in Iran. It is suggested to improve stability of health policies, interaction of the Ministry of Health with the health stakeholders, parents' awareness, utilization pattern of health services, and insurance coverage. With further studies, we can determine other aspects of the PKU screening process.

\section{Acknowledgments:}

This study was part of a PhD thesis supported by Tehran University of Medical Sciences. The authors appreciate members of the genetic department at the Ministry of Health and Medical Education for their assistance.

\section{Conflict of Interest:}

There is no conflict of interest to be declared.

Authors' contributions:

All authors contributed to this project and article equally. All authors read and approved the final manuscript.

\section{References:}

1) Banta-Wright SA, Kodadek SM, Steiner RD, Houck GM. Challenges to breastfeeding infants with phenylketonuria. J Pediatr Nurs. 2015; 30(1): 219-26. doi: 10.1016/j.pedn.2014.05.003. PMID: 24952998.

2) Soleymani Z, Keramati N, Rohani F, Jalaei S. Factors Influencing Verbal Intelligence and Spoken Language in Children with Phenylketonuria. Indian Pediatr. 2015; 52(5): 397-401. doi: 10.1007/s13312015-0644-8. PMID: 26061925.

3) Mei L, Song P, Xu L. Newborn screening and related policy against Phenylketonuria in China. Intractable Rare Dis Res. 2013; 2(3): 72-6. doi: 10.5582/irdr.2013.v2.3.72. PMID: 25343107, PMCID: PMC4204551.

4) Groselj U, Tansek MZ, Smon A, Angelkova N, Anton D, Baric I, et al. Newborn screening in southeastern Europe. Mol Genet Metab. 2014; 113(1-2): 42-5. doi: 10.1016/j.ymgme.2014.07.020. PMID: 25174966.

5) Padilla CD, Krotoski D, Therrell BL Jr. Newborn screening progress in developing countries--overcoming internal barriers. Semin Perinatol. 2010; 34(2): 145-55. doi: 10.1053/j.semperi.2009.12.007. PMID: 20207264.

6) Groselj U, Tansek MZ, Battelino T. Fifty years of phenylketonuria newborn screening - A great success for many, but what about the rest? Mol Genet Metab. 2014; 113(1-2): 8-10. doi: 10.1016/j.ymgme.2014.07.019. PMID: 25174964.

7) Karamifar H, Ordoei M, Karamizadeh Z, Amirhakimi GH. Incidence of neonatal hyperphenylalaninemia in Fars province, South Iran. Iran J Pediatr. 2010; 20(2): 216-20. PMID: 23056707, PMCID: PMC3446017.

8) Asadollah H, Falahzadeh MH, Kazerouni HR, Ganj Karimi AH. Incidence of phenylketonuria in southern Iran. Iran J Basic Med Sci. 2010; 35(2): 137-9.

9) Aghasi P, Setoodeh A, Sayarifard A, Rashidiyan M, Sayarifard F, Rabbani A, et al. Intellectual and Developmental Status in Children With Hyperphenylalaninemia and PKU Who Were Screened in a National Program. Iran J Pediatr. 2015; 25(6): 3033. doi: 10.5812/ijp.3033. PMID: 26635939, PMCID: PMC4662839.

10) Elbualy M, Bold A, De Silva V, Gibbons U. Congenital hypothyroid screening: the Oman experience. J Trop Pediatr. 1998; 44(2): 81-3. PMID: 9604594. 
11) Dhondt JL, Farriaux JP, Sailly JC, Lebrun T. Economic evaluation of cost-benefit ratio of neonatal screening procedure for phenylketonuria and hypothyroidism. J Inherit Metab Dis. 1991; 14(4): 633-9. PMID: 1749228.

12) Ben Romdhane H, Tlili F, Skhiri A, Zaman S, Phillimore P. Health system challenges of NCDs in Tunisia. Int J Public Health. 2015; 60(1): 39-46. doi: 10.1007/s00038-014-0616-0. PMID: 25399240.

13) Moshiri E. Using policy analysis methods and heuristic generalization approaches to provide a rich understanding of the mismatch between development of the referral system and the development of the PHC network in Iran's health care system: Identifying appropriate policy making theories [PhD Thesis]: Tehran University of medical sciences. 2015; 242.

14) Ozalp I, Coşkun T, Tokatli A, Kalkanoglu HS, Dursun A, Tokol S, et al. Newborn PKU screening in Turkey: at present and organization for future. Turk J Pediatr. 2000; 43(2): 97-101. PMID: 11432505.

15) Han YJ, Lee DH. Measures to Improve Newborn Screening System in Korea. Available from: https://www.kihasa.re.kr/common/filedown.do?seq=33013

16) Rashidiyan A. Policy challenges and the need to create coherent structures to help the evidence base decision making on health system. Hakim Res J. 2013; 16(3): 258-61.

17) Kalisch BJ, Lee H, Salas E. The development and testing of the nursing teamwork survey. Nurs Res. 2010; 59(1): 42-50. doi: 10.1097/NNR.0b013e3181c3bd42. PMID: 20010044.

18) Salas E, Diaz Granados D, Weaver SJ, King H. Does team training work? Principles for health care. Acad Emerg Med. 2008; 15(11): 1002-9. doi:10.1111/j.1553-2712.2008.00254. PMID: 18828828.

19) Chakraborti C, Boonyasai RT, Wright SM, Kern DE. A systematic review of teamwork training interventions in medical student and resident education. J Gen Intern Med. 2008; 23(6): 846-53. doi: 10.1007/s11606-008-0600-6. PMID: 18386100, PMCID: PMC2517885.

20) Padilla CD, Therrell BL. Newborn screening in the Asia Pacific region. J Inherit Metab Dis. 2007; 30(4): 490-506. doi: 10.1007/s10545-007-0687-7. PMID: 17643195.

21) Mei L, Song P, Xu L. Newborn screening and related policy against Phenylketonuria in China. Intractable Rare Dis Res. 2013; 2(3): 72-6. doi: 10.5582/irdr.2013.v2.3.72. PMID: 25343107, PMCID: PMC4204551.

22) Borrajo GJ. Newborn screening in Latin America at the beginning of the 21 st century. J Inherit Metab Dis. 2007; 30(4): 466-81. doi: 10.1007/s10545-007-0669-9. PMID: 17701285.

23) Han YJ, Lee DH, Kim JW. Newborn screening in Korea. Southeast Asian J Trop Med Public Health. 2003; 34(3): 81-4. PMID: 15906703.

24) Aye R, Wyss K, Abdualimova H, Saidaliev S. Illness costs to households are a key barrier to access diagnostic and treatment services for tuberculosis in Tajikistan. BMC Res Notes. 2010; 3(1): 340. doi: 10.1186/1756-0500-3-340. PMID: 21172015, PMCID: PMC3022814.

25) Van Doorslaer E, O'Donnell O, Rannan-Eliya RP, Somanathan A, Adhikari SR, Garg CC, et al. Effect of payments for health care on poverty estimates in 11 countries in Asia: an analysis of household survey data. Lancet. 2006; 368(9544): 1357-64. doi: 10.1016/S0140-6736(06)69560-3. PMID: 17046468.

26) Russell S. The economic burden of illness for households in developing countries: a review of studies focusing on malaria, tuberculosis, and human immunodeficiency virus/acquired immunodeficiency syndrome. Am J Trop Med Hyg. 2004; 71(2): 147-55. PMID: 15331831.

27) Kazemiyan M, Javadi Nasab H. Socio-economic Determinants of Health Expenditure for Low-income Households in the Informal Sector. J Kerman Univ Med Sci. 2014; 21(2): 151-61.

28) Huang MC, Lee CK, Lin SJ, Lu IC. Parental consent for newborn screening in southern Taiwan. J Med Ethics. 2005; 31(11): 621-4. doi: 10.1136/jme.2004.010074. PMID: 16269553, PMCID: PMC1734047.

29) Campbell E, Ross LF. Parental attitudes regarding newborn screening of PKU and DMD. Am J Med Genet A. 2003; 120(2): 209-14. doi: 10.1002/ajmg.a.20031. PMID: 12833401.

30) Alberta Health and Wellness, Community and Population Health Division Alberta Newborn Metabolic Screening Program Policy Document. $2010 . \quad$ Available from: http://www.health.alberta.ca/documents/Newborn-Metabolic-Screening-Policy-2010.pdf

31) Negar M, Badiee Aval S, Hosseini Yazdi SMR, Norouzi F, Mina T. The Epidemiological and Clinical Study of Phenylketonuria (PKU) Patients in Khorasan, North-eastern Iran. IJN. 2015; 6(1): 18-22.

32) Eshraghi P, Abaskhanian A, Mohammadhasani and A. Characteristics of patients with phenylketonuria in Mazandaran Province, northern, Iran. Caspian J Intern Med. 2010; 1(2): 72-4.

33) Vela-Amieva M, Ibarra-González I, Fernández-Lainez C, Monroy-Santoyo S, Guillén-López S, BelmontMartinez L, et al. Causes of delay in referral of patients with phenylketonuria to a specialized reference center in Mexico. J Med Screen. 2011; 18(3): 115-20. doi: 10.1258/jms.2011.011028. PMID: 22045819. 
34) Stranieri I, Takano OA. Evaluation of the Neonatal Screening Program for congenital hypothyroidism and phenylketonuria in the State of Mato Grosso, Brazil. Arq Bras Endocrinol Metabol. 2009; 53(4): 446-52. doi: 10.1258/jms.2011.011028. PMID: 19649383.

35) Adesa AE, Walkera J, Jonesb R, Smithc I. Coverage of neonatal screening: failure of coverage or failure of information system. Arch Dis Child. 2001; 84(6): 476-9. doi:10.1136/adc.84.6.476.

36) Tomasi E, Facchini LA, Maia MF. Health information technology in primary health care in developing countries: a literature review. Bull World Health Organ. 2004; 82(11): 867-74. PMID: 15640923, PMCID: PMC2623061.

37) Mirkhalafzadeh M, Haddadpoor A, Mazroei F, Nasri M, Bahrami G. Designing and Developing a Software for Hypothyroidism and Phenylketonuria Screening in Newborns. J Mazandaran Univ Med Sci. 2014; 24(120): 148-9. 